\title{
Incidèncias da morte no cancioneiro oral infantil português
}

The Presence of Death in the Portuguese oral tradition of children's poetry

Carlos Nogueira

Universidade de Vigo (Cátedra José Saramago)

Resumo: No mundo Ocidental, são muitas as vozes que nos vão lembrando, de tempos a tempos, que já não sabemos construir-nos vivendo e encarando a morte com frontalidade e dignidade. Assumiu-se que falar da morte é produzir uma dor ou um mal-estar que colidem com os valores da nossa sociedade, cada vez mais voltada para o culto da beleza e da eterna juventude. Até sensivelmente às décadas de 70 ou 80 do século passado, a sociedade portuguesa, sobretudo a mais rural, não escondia dos mais novos as doenças, o envelhecimento e a morte dos entes queridos. Hoje, estes são temas praticamente proibidos e por isso muitas crianças são educadas sem o conhecimento da morte. Partindo desses pressupostos, abordaremos nesta comunicação a questão da morte na poesia oral e tradicional infantil portuguesa moderna e contemporânea. Veremos, em particular, se a morte aparece mais como personagem ou mais como acontecimento, reflectiremos sobre os seus tipos e as suas incidências semânticas, simbólicas e pragmáticas, e discutiremos se vale a pena trazer estes textos para o contexto educativo.

Palavras-Chave: Morte. Cancioneiro oral infantil. Portugal.

Abstract: In Western countries, we are often reminded, from time to time, of our growing inability to confront death with resolve and dignity. There is a common assumption that but to speak of death is to produce pain and discomfort, emotions that are blatantly incompatible to the predominant standard patterns of felling of our modern societies, as the cultivation of beauty and the ideal of eternal youth. At least until the decades of 1870 and 1880 , the Portuguese society - particularly the one that was still living in the countryside - had a much less restrictive standing towards death and the realities of aging and disease. Today, these topics and themes are thought mostly as inappropriate and, as a result, an increasing number of children are nowadays raised in total unawareness of death. Our investigation will examine the presence of the death theme in modern and contemporary oral children poetry in Portugal. We will examine, in particular, whether death appears more as a character or as an event in these stories, and reflect as well on 
its types and its semantic, symbolic and pragmatic scope. We will finally consider the possibility of integrating these texts into the context of learning and schooling. Keywords: Death. Oral tradition. Portuguese cancioneiro. Nursery rhymes.

No actual cancioneiro oral infantil português não há já vestígios de textos em que a morte é essa personagem complexa e enigmática que sempre fez parte de mitos, lendas e contos tradicionais; e a morte como acontecimento (função cardinal ou micro-evento) também não é pro-

Carlos priamente muito contemplada. Mas isto não significa que as crianças Nogueira portuguesas não podem ter qualquer contacto com poemas tradicionais em que a morte cumpre a sua função de acto de linguagem que cria significados para a vida individual e da sociedade. Esta carência pode ser em parte suprida através da leitura e do aproveitamento didáctico de textos literários orais como os que analisamos neste artigo.

Textos, dirigidos em especial ao leitor infantil e juvenil, de escritores como Sophia de Mello Breyner e de António Mota dizem-nos que assumir e pensar a morte pode ser essencial para a construção de uma vida mais livre e integral, despojada de algumas das obsessões que nos afastam de valores fundamentais como a dignidade, a solidariedade e o amor (NOGUEIRA, 2012, p. 93-111). Encobrir e simplificar o desaparecimento de alguém a uma criança é promover o que, em linguagem antropológica e sociológica, se designa por "morte social". A vida de quem morre deixa de poder ser significativa para os vivos e, em especial, para as crianças e os jovens, cujo universo de referências fica necessariamente empobrecido.

Hoje, a criança é protegida de tudo o que se relaciona com a verdade e as imediações da morte. Os avós padecem e morrem sozinhos num hospital sem ver os netos, em casa não se fala de morte porque dizer a morte é produzí-la. De um tempo em que os mais novos eram afastados dos hospitais por receio de contágios, passou-se, numa época em que a ciência reduziu os riscos de transmissão de doenças, ao apagamento da morte da visão e da memória infantis.

Janet Goodall observa que esta atitude contraria a vontade das crianças, que, regra geral, não querem ser excluídas dos rituais que acompanham a morte de um familiar ou amigo. Não só se tem concluído que a exclusão é mais perturbadora do que a inclusão, e que "Parents and children belong together, even (perhaps particularly) when one of them is in hospital" (2000, p. 232-233), como também se percebe cada 
vez mais que "A bright child, or one that has endured much, will mature more quickly, as experience accelerates understanding" (GOODALL, 2000 , p. 235). Não falar da morte e da sua irredutibilidade quando alguém está a morrer pode levar a que a criança se sinta responsável pelo ambiente de pesar e desconforto que se cria; e pode por isso implicar que ela veja uma punição numa simples ida a um centro de saúde ou a um hospital para fazer exames de rotina (GOODALL, 2000, p. 234).

O efeito desta fuga da realidade da morte, como defendem especialistas de diversas áreas, é negativo: entre a vida, o amor e a morte, entre a criança, o jovem e o adulto, cria-se um vazio que prejudica o equilíbrio individual e a coesão social. Freud nota que impedir o trabalho do luto de que decorre a aceitação da perda de uma pessoa pode conduzir a um estado patológico que, em certos casos, resulta no suicídio (GOODALL, 2000, p. 288-301).

Incidências da morte no cancioneiro oral infantil português

Viver abruptamente a morte sem ter feito lutos sucessivos significa vir a sofrê-la mais cruelmente e traumaticamente. Aceitá-la e vivê-la através da literatura é já, em parte, conhecê-la e compreendê-la. Aprender a ver a morte como uma componente fundamental da condição humana e da vida em geral emancipa o espírito e o corpo. Sem a imortalidade social, sem a vida dos mortos na memória dos descendentes e dos outros vivos, a morte transforma-se em lei absoluta que impede a realização mais integral do eu (TRESMONTANT, 1966).

Hoje, numa sociedade tecnológica que se rege como nunca pelo mito da eterna juventude, tende-se a proteger a criança até de uma adivinha tradicional sobre a morte, os mortos, o caixão, a velhice. Felizmente, nem todos os organizadores de antologias de adivinhas para a infância partilham desta opinião, e nem todos os encarregados de educação, educadores de infância e professores evitam usar tais textos, que estão disponíveis em obras como o Livro das Adivinhas (1921), de Augusto César Pires de Lima, que conta já com mais de dez edições, Adivinhas Populares Portuguesas (1988), de Viale Moutinho, também muito lido e reeditado várias vezes, Trava-Línguas e Mais Adivinhas Coloridas (2009), de Tiago Salgueiro, ou Adivinhas, Adivinhas. 150 Adivinhas Populares (1991), de Luísa Ducla Soares. Estes dois últimos títulos são sem dúvida os mais conhecidos, por se inscreverem explicitamente no âmbito da literatura de recepção infantil.

Uma adivinha (um poema) como "Quem o faz é para vender,/ Quem o vende não se serve/ E quem se serve não o vê" (SOARES, 1994, p. 26), cuja solução é o "caixão", ou "O que é fazem todos ao mesmo tempo, velhos, novos e crianças?", que tem como resposta "envelhecem" 
ou "envelhecer", lembram-nos como as crianças portuguesas viviam muito de perto a morte de vizinhos e familiares. Criando uma ligação afectiva e moral com os mais velhos e com os mortos, elas enfrentavam a morte, e, de certo modo, venciam-na. A partir da morte do outro, do caos ou do vazio que ela sempre traz, os mais novos repunham a ordem e construíam a sua vida, entendendo-a dentro do ciclo natural de vida e morte (nascimento, infância, juventude, idade adulta, velhice e morte). Não se marginalizava, como hoje, essa imagem da morte, tanto mais terrível quanto mais dela nos alhearmos, que é a velhice, vista na

Carlos sociedade moderna sobretudo como sinónimo de decadência e anúncio Nogueira da morte. As idades mais avançadas, através da linguagem, das emoções e dos afectos que se estabelecem entre as pessoas seniores e os outros, pode transformar-se numa idade positiva e criadora.

O espaço e o tempo do envelhecimento e da morte do outro traziam à criança um tempo forte. As adivinhas sobre o caixão, a morte e o envelhecimento contribuíam para a existência da sabedoria que se aprende com a consciência da velhice e da morte, de cuja realidade biológica e social as crianças não eram afastadas. Hoje é fácil retomar o "papel educativo" (LIMA, 1994, p. 11) destas adivinhas, que se encontram nas obras que referimos. Comparar versões, ilustrá-las, expô-las e usá-las tanto em unidades didácticas como em jogos que envolvam alunos da mesma turma ou de várias turmas (ou de escolas diferentes) são apenas algumas das inúmeras possibilidades didácticas destes textos. Estas adivinhas, mais do que no passado, são um modo de dizer um interdito social:

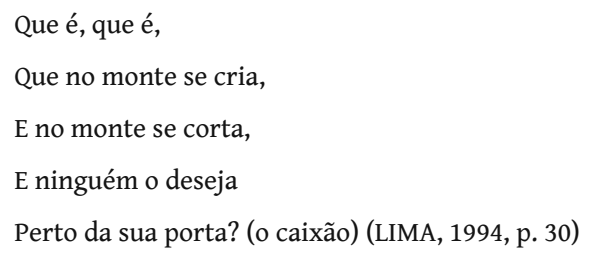


A morte, na televisão e nos videojogos, vulgarizou-se. Contudo, na vida de todos os dias, a morte física é, hoje, o maior dos interditos. Não é por acaso que este texto do cancioneiro, e do cancioneiro infantil e juvenil, tem agora uma existência rara ou não circula minimamente entre as crianças e os jovens portugueses:

À morte ninguém escapa.

Incidências

Morre o Rei, morre o Bispo

da morte no

E morre o Papa.

cancioneiro

Mas hei-de escapar eu.

oral infantil

Compro uma panela,

português

Custa-me um vintém,

Meto-me dentro dela

E tapo-a muito bem.

Passa a morte, olha e diz:

Aqui não há ninguém.

Minha senhoras e meus senhores,

Escapei à morte por um vintém (OLIVEIRA, 2004, p. 38) ${ }^{1}$.

De exorcismo lúcido e lúdico, de prática ritual que estabelecia entre a vida e a morte um diálogo constante, À Morte Ninguém Escapa passou a existir quase exclusivamente em colectâneas e monografias. Em 1988, todavia, Luísa Ducla Soares fixou esta versão no livro Lenga Lengas:

\author{
À morte ninguém escapa, \\ Nem o rei, nem o papa, \\ Mas escapo eu. \\ Compro uma panela, \\ Custa-me um vintém, \\ Meto-me dentro dela \\ E tapo-me muito bem, \\ Então a morte passa e diz: \\ - Truz, truz! Quem está ali?
}

1 Também já não é uma prática comum transmitir aos mais novos contos populares em que as figuras da Morte ou do morto aparecem a lembrar ao ser humano que a vida tem um fim. Mas há antologias a que qualquer educador pode recorrer facilmente. É o caso do vol. I da Antologia de Contos Populares, de Alexandre Parafita, que reúne textos como "Levanta-te, ó homem morto!", "O rapaz e a caveira", "A morte madrinha", “A promessa da comadre morte" e "A miséria e a morte" (2001, p. 56-57, p. 83 e p. 200-204). 
- Aqui, aqui não está ninguém.

- Adeus, meus senhores,

Passem muito bem. (SOARES, 1997, p. 4)

Também a lenga lenga acumulativa 0 Castelo de Chuchurumel, que fazia parte do cancioneiro oral infantil português até sensivelmente às décadas de 60 ou 70 do século passado, desapareceu da tradição oral. Mas faz parte de colectâneas preparadas a pensar nos leitores mais novos e por isso continua viva. É, como os textos que já aqui vimos, um Carlos poema que guarda a memória da vivência da morte como acontecimenNogueira to natural e quotidiano. A consciência da morte que os mais novos assimilavam a partir da relação com os adultos tinha neste texto longo e 20 inventivo uma representação literária que ajudava os mais novos (e não só) a regular os seus valores por referência aos grandes temas humanos do envelhecimento, da passagem do tempo, da efemeridade da vida e da morte. Sempre que $O$ Castelo de Chuchurumel é lido e comentado, a partir das (poucas) obras que o acolhem, essa função é activada²; e pode tornar-se ainda mais presente e actuante se se recuperar o jogo, que pode ser enriquecido de múltiplas formas (através do recurso à declamação, à dramatização simples ou com recurso a cenários e a adereços, etc.):

$$
\begin{aligned}
& \text { Aqui está a chave } \\
& \text { Que abre a porta } \\
& \text { Do castelo } \\
& \text { De Chuchurumel. } \\
& \text { Aqui está o cordel } \\
& \text { Que prende a chave } \\
& \text { Que abre a porta } \\
& \text { Do castelo } \\
& \text { De Chuchurumel. } \\
& \text { Aqui está o sebo } \\
& \text { Que unta o cordel } \\
& \text { Que prende a chave }
\end{aligned}
$$

2 Teófilo Braga nota que este texto integrava um jogo em que se entregava "uma chave de mão em mão, dizendo uma parlenda que cada qual repete acrescentando-a à maneira dos contos de acumulação, e paga pranda no caso de engano" (1985, p. 251). 
Que abre a porta

Do castelo

De Chuchurumel.

Aqui está o rato

Que roeu o sebo

Que unta o cordel

Incidências

Que prende a chave

da morte no

Que abre a porta

cancioneiro

Do castelo

oral infantil

De Chuchurumel.

português

Aqui está o gato

Que comeu o rato

Que roeu o sebo

Que unta o cordel

Que prende a chave

Que abre a porta

Do castelo

De Chuchurumel.

(...)

Aqui está o carniceiro

Que matou o boi

Que bebeu a água

Que apagou o lume

Que queimou o pau

Que bateu no cão

Que mordeu o gato

Que comeu o rato

Que roeu o sebo

Que unta o cordel

Que prende a chave

Que abre a porta

Do castelo

De Chuchurumel. 


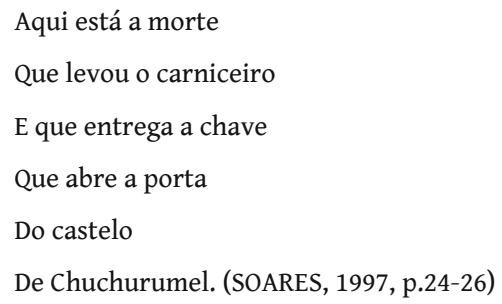

A morte não surge n'o Castelo de Chuchurumel apenas como uma consequência natural da vida; inexorável, ela é a maior das forças, e o Carlos ser humano, que aqui aparece na figura de um carniceiro, nada pode Nogueira contra ela. O carniceiro, um matador, é morto pela morte.

A morte inspira terror e sofrimento, mas também dá significado à vida. Daí o interesse humano e social destes poemas e o seu alcance pedagógico e didáctico. A morte real, a morte de um ser vivo que nos é próximo, nunca é vulgar. Por isso é que a morte de João Ratão, na História da Carochinha, não pode ser comparada a outras mortes que aparecem nos cancioneiros infantis moderno e contemporâneo; não se trata de uma morte que suscita o riso socializador ou que se evoca de modo mais ou menos mecânico, como nestas rimas de jogos: “Tão, balalão/ Morreu o Simão!/ Ficaram os filhos,/ Comeram o pão” (BRAGA, 1985, p. 218); “Ó-taí-ta-á,/ Quem está morto/ Morto está" (NOGUEIRA, 2002, p. 262); "Pim, pão, pum,/ Cada bola mata um,/ Lá em cima no Huambo/ Está um frasco com remédio,/ Quem bebeu morreu" (NOGUEIRA, 2002, p. 264); “Tio Zé da Pitarraça/ Tem piolhos na gravata./ Quantos tira, quantos mata?/ Foi na rua vinte e quatro/ Que a mulher matou o gato/ Com a ponta do sapato,/ O sapato derreteu/ E a mulher morreu" (NOGUEIRA, 2002, p. 265); e "Mão morta/ Mão morta,/ Vai bater àquela porta/ Que está lá o mau/ Que te dá com o pau"3. A morte de João Ratão, que desencadeia uma série de efeitos imprevisíveis e impressionantes, apresentados no final numa lengalenga acumulativa, nada tem de acontecimento insignificante ou simplesmente jocoso; é uma morte trágica, a morte de um mundo e, alegoricamente, a morte do mundo:

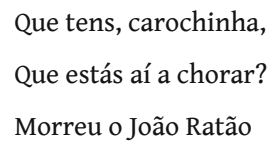

3 Ouvimos esta versão em Vila Nova de Gaia, na freguesia de Santa Marinha. Já conhecíamos esta, que aparece em várias recolhas e estudos publicados em finais do século XIX: "Mão morta/ Mão morta,/ Te bate na porta./ Se não tens que lhe dar/ Dá-lhe sal do mar” (BRAGA, 1985, p. 247). 
E por isso estou a chorar.

E eu que sou a tripeça

Ponho-me a dançar.

Diz dali uma porta:

Que tens tu, tripeça,

Incidências

Que estás a dançar?

da morte no

Morreu o João Ratão

cancioneiro

Carochinha está a chorar.

oral infantil

E eu que sou a tripeça

português

Pus-me a dançar.

E eu que sou a porta

Ponho-me a abrir e a fechar.

(...)

Vieram os passarinhos para descansar no pinheiro e viram-no arrancado e disseram:

Que tens tu, pinheiro,

Que estás no chão?

Morreu o João Ratão,

Carochinha está a chorar.

A tripeça está a dançar,

A porta a abrir e a fechar,

A trave quebrou-se,

E eu arranquei-me.

E nós que somos passarinhos

Vamos tirar os nossos olhinhos. (COELHO, 1999, p. 81-82)

José Leite de Vasconcelos, numa nota a uma das versões que coligiu da História da Carochinha, diz-nos que "Toda a natureza, e a sociedade, toma luto pela morte de um rato!" (1963, p. 70). Morrendo o João Ratão, um rato, um animal considerado menor, insignificante e desprezível na maioria das culturas, morre ou degenera todo um universo (GUIMARÃES, 2004, p. 395-417): o mundo material, construído pelo ser humano (a tripeça, a porta, a cântara), o animal (a carochinha chora, inconsolável; os 
pássaros cegam-se e assim condenam-se a uma morte certa), o natural (vegetal: o pinheiro; o elemento água) e ainda o humano (as crianças quebram os cantarinhos, e a rainha e o rei impõe-se gestos humilhantes):

E foram os meninos para o palácio e a rainha perguntou-lhes:

Que tendes, meninos,

Que quebrastes os cantarinhos?

Morreu o João Ratão,

Carlos

A Carochinha está a chorar.

Nogueira

A tripeça a dançar,

A porta a abrir e a fechar,

24

A trave quebrou-se,

o pinheiro arrancou-se,

Os passarinhos tiraram os olhinhos,

A fonte secou-se,

E nós quebramos os cantarinhos.

Pois eu que sou a rainha

Andarei em fralda pela cozinha.

Diz dali o rei:

E eu vou arrastar o c...

Pelas brasas. (COELHO, 1999, p. 84)

O conto História da Carochinha continua a ser contado às crianças, em especial nos jardins de infância, mas suprimiu-se a sequência em verso da versão coligida por Adolfo Coelho. Entende-se que esta parte não é adequada aos mais novos, que poderiam impressionar-se com a atitude dos pássaros, que arrancam os olhos, e das fontes, que secam, com o caos que advém de uma simples morte. Mas há crianças um pouco mais velhas que têm acesso a esta versão na sala de aula, já que certos professores querem aproveitar o seu valor educativo e formativo. Enquanto que as crianças do ensino pré-escolar se fixam sobretudo na ideia de que a gula é um vício ${ }^{4}$, leitores mais velhos podem ser conduzidos a reflectir sobre a dimensão mais cósmica e ecológica desta narrativa.

4 Não é por acaso que da interacção entre uma mãe e uma filha de seis anos resultou este final, que explicíta claramente a moral das versões mais breves da História da Carochinha: "Desta simples história/ Fique a seguinte lição/ Ninguém seja tão guloso/ Como era o João Ratão" (MATA \& PINTO. Disponível na Internet). 
Um adulto purista e paternalista verá nos poemas e versos que comentámos uma violação da sensibilidade dos mais novos. Já um leitor informado e evoluído, especialista ou não, entenderá que estes textos constituem um valioso contributo para a formação da identidade dos jovens leitores. Trata-se de fazer sobressair o valor ético e sapiencial da morte, que só pode ser contrariada por uma existência intelectual, espiritual e livre. É na consciência da finitude da vida que reside a possibilidade de uma existência plenamente vivida. A ética da morte destes textos é, afinal, uma ética para a vida.

\section{REFERÊNCIAS}

BRAGA, Teófilo. A linguagem emocional. Parlendas e jogos infantis. 0 povo Incidências da morte no cancioneiro oral infantil português português nos seus costumes, crenças e tradições. Vol. I. Prefácio de Jorge Freitas Branco. Lisboa: Publicações Dom Quixote, 1985, pp. 209-273.

COELHO, Adolfo. Contos populares portugueses. 5. ed. Lisboa: Publicações Dom Quixote, 1999.

FREUD, Sigmund. Trauer und melancholie. Internationale zeitschrift für ärztliche psychoanalyse, IV, 6, 1917, p. 288-301.

GOODALL, Janet. Grieving parents, grieving children. In: Gillian Avery; Kimberley Reynolds (ed.). Representations of childhood death. Hampshire and London / New York: Macmillan Press / St. Martin's Press, 2000, p. 225-238.

GUIMARÃES, Ana Paula. A história das histórias: a carochinha. In: Ana Paula Guimarães, João L. Barbosa e Luís Cancela da Fonseca (orgs.). Falas da Terra. Natureza e ambiente na tradição popular portuguesa. Lisboa: Edições Colibri / Instituto de Estudos de Literatura Tradicional, 2004, p. 395-417.

MATA, Lília; PINTO, Carolina. História da carochinha em verso. Uxy. Web. 31 July 2012.

LIMA, Augusto César Pires de. O livro das adivinhas. 7. ed. Lisboa: Editorial Notícias, 1994. 
MOUTINHO, Viale. Adivinhas populares portuguesas. 2. ed. revista e aumentada. Porto: Editorial Domingos Barreira, 1990.

NOGUEIRA, Carlos. Cancioneiro popular de Baião. Vol. II. Baião: Cooperativa Cultural de Baião - Fonte do Mel, 2002.

Death in literature for children and young people. Portuguese Studies, 28, 2012, p. 93-111.

Carlos OLIVEIRA, José Alberto. O bestiário. Lisboa: Assírio \& Alvim, 2004. Nogueira

PARAFITA, Alexandre. Antologia de contos populares. Vol. I. Posfácio de Ana Paula Guimarães. Lisboa: Plátano Editora, 2001.

SALGUEIRO, Tiago. Trava-línguas e mais adivinhas coloridas. Ilustrações de Elsa Navarro. Porto: Ambar, 2009.

SOARES, Luísa Ducla (recolha e selecção). Adivinhas, adivinhas. 150 adivinhas populares. Ilustrações de Sofia Lucas. 3. ed ed. Lisboa: Livros Horizonte, 1994.

. Lenga lengas. Ilustra ções de Sofia Castro. 2. ed. Lisboa: Livros Horizonte, 1997.

TRESMONTANT, Claude. Comment se pose aujourd'hui le problème de l'existence de Dieu?.Paris: Seuil, 1966.

VASCONCELOS, José Leite de. Contos populares e lendas. Coordenação de Alda da Silva Soromenho e Paulo Caratão Soromenho. Vol. I. Coimbra: Por Ordem da Universidade, 1963.

- Recebido em abril / 2017

- Aceite em junho / 2017 